\title{
Effects of continuous aerobic exercise on lung function and quality of life with asthma: a systematic review and meta-analysis
}

\author{
Xinggui Wu", Shiyuan Gao", Yixin Lian \\ Department of Respiration Medicine, The Second Affiliated Hospital of Soochow University, Suzhou, China \\ Contributions: (I) Conception and design: Y Lian, X Wu; (II) Administrative support: None; (III) Provision of study materials or patients: Y Lian, X \\ Wu, S Gao; (IV) Collection and assembly of data: Y Lian, X Wu, S Gao; (V) Data analysis and interpretation: Y Lian, X Wu, S Gao; (VI) Manuscript \\ writing: All authors; (VII) Final approval of manuscript: All authors. \\ "These authors contributed equally to this work. \\ Correspondence to: Yixin Lian. Department of Respiration Medicine, The Second Affiliated Hospital of Soochow University, San Xiang Road 1005, \\ Suzhou 215004, China. Email: lynelian@163.com.
}

Background: Despite the obvious benefits of aerobic exercise for asthmatic patients, controversies persist. The current study evaluated the effectiveness of continuous aerobic exercise on lung function and quality of life of asthmatic patients.

Methods: We searched PubMed, EMBASE, and the Cochrane Central Register of Controlled Trials databases up to May 2019 and included randomized controlled trials (RCTs) of asthmatic patients intervened with whole body continuous aerobic exercise (moderate intensity, at least 20 minutes and two times a week, over a minimum period of four weeks), in which the endpoint measures were lung function and asthmarelated quality of life. A fixed-effects model $\left(\mathrm{I}^{2} \leq 50 \%\right)$ or random-effects model $\left(\mathrm{I}^{2}>50 \%\right)$ was applied to calculate the pooled effects according to the $\mathrm{I}^{2}$-and Chi-squared $\left(\chi^{2}\right)$ test, funnel plots were quantified to present publication bias, and a $\mathrm{P}$ value $<0.05$ was statistically significant.

Results: Eventually, 22 trials conformed to the selection criteria. In the aerobic exercise group, the forced expiratory volume improved in one second (FEV1) $\left(\mathrm{I}^{2}=10.2 \%\right.$, WMD: 0.12, $\left.\mathrm{P}=0.011\right)$, peak expiratory flow (PEF) $\left(\mathrm{I}^{2}=87.3 \%\right.$, WMD: 0.66, $\left.\mathrm{P}=0.002\right)$, forced vital capacity (FVC) $\left(\mathrm{I}^{2}=0.0 \%, \mathrm{WMD}: 0.18, \mathrm{P}<0.001\right)$, FVC/predict ( $\mathrm{I}^{2}=3.9 \%$, WMD: $\left.4.3, \mathrm{P}=0.014\right)$, forced expiratory flow between $25 \%$ and $75 \%$ of vital capacity $\left(\mathrm{FEF}_{25-75 \%}\right)\left(\mathrm{I}^{2}=0.0 \%\right.$, WMD: 9.6, $\left.\mathrm{P}=0.005\right)$, Asthma Quality of Life Questionnaire (AQLQ) $\left(\mathrm{I}^{2}=0.0 \%\right.$, WMD: 0.20, $\mathrm{P}=0.002)$, and Pediatric Asthma Quality of life Questionnaire (PAQLQ) $\left(\mathrm{I}^{2}=72.1 \%\right.$, WMD: $0.81, \mathrm{P}<0.001)$, respectively, while no statistical significance existed in FEV1\%predict $\left(\mathrm{I}^{2}=36.0 \%\right.$, WMD: 0.68 , $\mathrm{P}=0.312)$ and $\mathrm{FEV1/FVC}$ ratio $\left(\mathrm{I}^{2}=0.0 \%\right.$, WMD: $\left.0.27, \mathrm{P}=0.443\right)$ compared with the control group. When the exercise mode was taken into account, we observed significant improvement in FEV1, PEF, and FVC in the swimming $(\mathrm{P}<0.05)$ or indoor treadmill $(\mathrm{P}<0.05)$ training group.

Conclusions: Our meta-analysis proved that regular continuous aerobic exercise benefits asthma patients on FEV1, PEF, FVC, FVC\% pred, $\mathrm{FEF}_{25-75 \%}$, and quality of life, and was well tolerated, while there were no improvements in FEV1\% pred and FEV1/FVC\%. As such, swimming and treadmill training may be appropriate options.

Keywords: Asthma; aerobic exercise; pulmonary function; quality of life; meta-analysis

Submitted Sep 01, 2019. Accepted for publication Jul 22, 2020.

doi: $10.21037 /$ jtd-19-2813

View this article at: http://dx.doi.org/10.21037/jtd-19-2813

(C) Journal of Thoracic Disease. All rights reserved. 


\section{Introduction}

Asthma is a common chronic inflammatory pulmonary disorder resulting in a detrimental impact on the physical, emotional, and social daily life activity of patients (1). Asthmatics should have a reliever or controller medications. However, a variety of adverse events can occur, especially in children with asthma (2-4). To date, considerable research has been devoted to asthma's characteristics and nonpharmacologic interventions. Pulmonary rehabilitation, a reputed feasible method of exercise training, education, and behavioral change, is designed to improve the physical and psychological condition of those with chronic respiratory disease and promote long-term adherence to healthenhancing behaviors $(5,6)$. As an essential component of pulmonary rehabilitation, physical exercise demonstrated improvement in cardiovascular function, physical activity levels, and sociological benefits in previous studies (7-9).

Reports of physical exercise interventions vary methodologically in terms of the mode, intensity, frequency, and duration (10). The Centers for Disease Control and Prevention and American College of Sports Medicine recommend at least 30 minutes of moderately intense physical activity five days per week or vigorously intense activity for a minimum of 20 minutes three days per week (11). Prior studies $(12,13)$ reported that the best method of increasing activity levels was spending more time on moderate-intensity exercise and less time on highintensity activity. Aerobic exercise is considered any form of physical activity that produces an increased heart rate and respiratory volume to meet the oxygen requirements of the activated muscles. Oxygen inhalation and demand are equal in the human body to achieve physiological equilibrium during training. In a mouse model of allergic asthma, moderately intense aerobic exercise attenuated lung inflammatory responses (14). Neder et al. (15) reported aerobic improvement and significant medication reduction with aerobic training in patients with moderate to severe asthma.

Systematic reviews have verified that physical training improved cardiopulmonary fitness, maximum oxygen uptake, asthma symptoms, and quality of life in asthmatic patients, with no adverse effects on lung function (16-19). Conversely, several emerging studies demonstrated improved asthma symptoms and lung function $(20,21)$ after aerobic exercise. Despite obvious benefits of aerobic exercise for asthmatic patients, controversies persist. We performed a meta-analysis for an exhaustive review of the available evidence on pulmonary function and quality of life between asthma and continuous aerobic exercise.

We present the following article in accordance with the PRISMA reporting checklist (available at http://dx.doi. org/10.21037/jtd-19-2813).

\section{Methods}

\section{Search strategy}

A comprehensive electronic search for aerobic exercise training trials in asthmatic patients was conducted in PubMed, EMBASE, and the Cochrane Central Register of Controlled Trials (CINAHL) containing the following retrieval strategies: "asthma AND (train* OR exercise* OR physical activity* OR aerobic exercise* OR pulmonary rehabilitation*)". There were no age, language, or date of publication restrictions.

\section{Selection criteria}

The inclusion criteria are as follows: The clinical diagnosis of asthma according to the Global Initiative for Asthma (GINA) recommendations or made by a physician and/or using objective criteria such as bronchodilator reversibility or both; any type of whole aerobic exercise lasting at least 20 minutes and two times per week for a minimum duration of 4 weeks; original trials in which continuous aerobic training and asthma were involved and a control group consisting of no intervention or receiving the same level of education or medication; and outcomes of trials for quantitative synthesis including pulmonary function and quality of life (QoL). We excluded studies that did not conform to whole body continuous aerobic physical training in asthma patients and did not contain randomized controlled trial designs or valid data. Two reviewers independently assessed the rationality of the included articles. In cases of dispute, agreement was reached through consultation.

\section{Outcome measures}

The primary endpoints were pulmonary function (FEV1, FEV1\% pred, FVC, FVC\% pred, PEF, $\mathrm{FEF}_{25-75 \%}$, and $\mathrm{FEV1/}$ $\mathrm{FVC} \%)$ and the secondary outcome was quality of life (QoL).

\section{Quality assessment and data extraction}

Two investigators evaluated the quality of the trials and 
the risk of bias using the Jadad Scale score (22) and the Cochrane Handbook for Systematic Reviews of Intervention Criteria (23), respectively. The characteristics of eligible articles were stated with the first author, publication, year, country, age, interventions, patients, and outcomes (Tables 1,2). Two pursuers independently extracted the sample size, mean value, and standard deviation of the outcome indicators. In cases of inconsistency, the results were discussed with a third researcher.

\section{Statistical analysis}

For the continuous variables, the standardized mean difference (SMD) or weighted mean difference (WMD) were calculated according to the uniformity of the measuring unit. The pooled effect size was described using forest plots, and a $\mathrm{P}$ value $<0.05$ was statistically significant. The heterogeneity of the studies was assessed via $\mathrm{I}^{2}$-and Chi-squared $\left(\chi^{2}\right)$ statistics, and a fixed-effects model was used to amalgamate the effect size when $\mathrm{I}^{2} \leq 50 \%$ or $\mathrm{P}>0.1$ in the $\chi^{2}$ statistics. We also attempted to find potential sources of heterogeneity through subgroup analysis or sensitivity analysis if significant heterogeneity $\left(\mathrm{I}^{2}>50 \%\right)$ emerged or incorporated heterogeneity using a random-effects model (23). Funnel plots were quantified to detect any publication bias $(\mathrm{P}$ value $<0.05)$ if there were sufficient articles (10 or more studies). All of the data analyses were completed using Stata 14.0 software.

\section{Results}

We identified 2,379 manuscripts from an initial search of the databases, and 1,517 citations remained after duplicates were removed. Of these, 1,359 were excluded after appraising the titles/abstracts. Based on full-text screening, we agreed on 25 articles for qualitative synthesis. Finally, 22 studies were incorporated into the meta-analysis due to insufficient data in 3 articles (Figure 1).

\section{Characteristics of eligible studies}

Twenty-two trials (24-45) involving the randomization of 874 participants assessing the effect of aerobic exercise on lung function or quality of life in asthmatic patients were published between 1990 and 2019. Of these, the patients in 12 articles $(25-27,29-32,34,36,41,44,45)$ were children. Six studies involved individuals with moderate or severe persistent asthma, and others had mild to moderate persistent asthma. The measurements of outcomes were recorded after a 6- to 16-week training run, and spirometric variables and quality of life of post-exercise intervention were compared between the exercise group and control group. In most of the studies, the training modes were cycling, treadmill walking, and swimming. One involved submaximal basketball, two included multiple aerobic exercises, and four trials did not refer to a specific form of exercise. The frequency of aerobic exercise training in 12 studies involved two sessions per week, while others studies mandated exercise 3 times a week. The exercise training sessions ranged from 20 to 90 minutes, and moderate exercise intensity was controlled by maintaining the heart rate between $50 \%$ and $80 \%$ of the maximum heart rate $(46,47)$ (HRmax) during exercise in the majority of the included trials (Tables 1,2).

\section{Methodologic quality assessment of the included trials}

All of the trials mentioned randomization, but many did not provide detailed information. In the Jadad Scale score, six studies were marked by four scores, eight studies were given three marks, and others scored two (Tables 1,2). The risk of bias is summarized in Figure 2. Low means that there was a plausible bias unlikely to seriously alter the results. High means that plausible bias occurred that can seriously weaken confidence in the results. Uncertain was stated if there were unclear risks of bias or if plausible bias could raise some doubts about the results (23). However, blinding of the participants and personnel was not regarded as a possible bias because the design of the study itself (exercise vs. no exercise) precluded blinding.

\section{Results of the meta-analysis}

We excluded several studies by Mendes et al. (in 2010, 2011) $(35,39)$ and Gonçalves et al. (33) from the current meta-analysis because of the presentation of medians and interquartile ranges in the relevant parameters. We were unable to clarify whether the participants enrolled in three studies would overlap because the subjects were recruited by the same researchers. A study by Farid et al. (28) could not be pooled due to the imprecise description of the variables. A study by Wicher et al. (36) was excluded due to obvious differences in the pre-study FEV1\% and FVC\%pred parameters between the exercise and control groups. A study by Andrade et al. (41) was removed because no valid data could be pooled. 


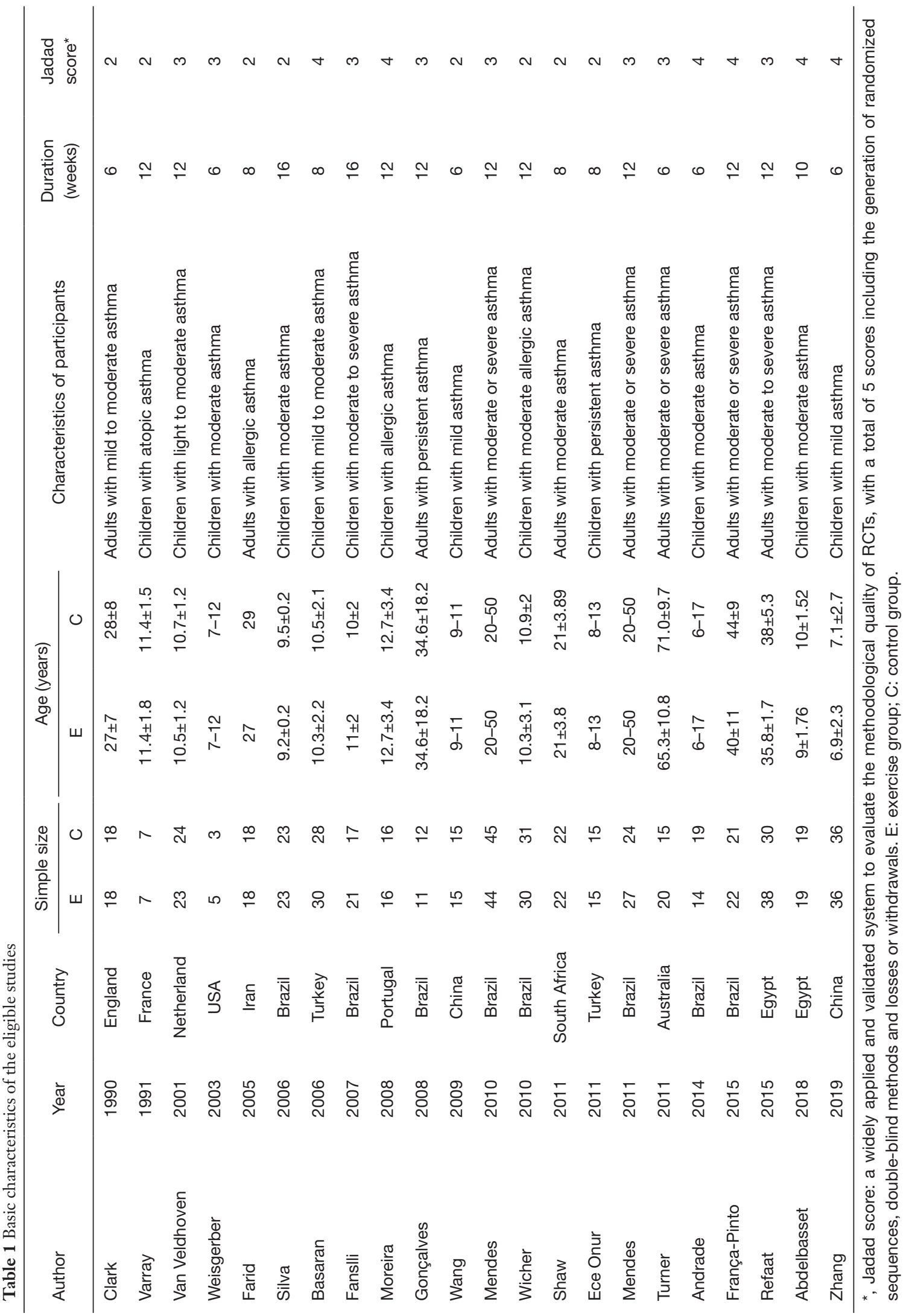




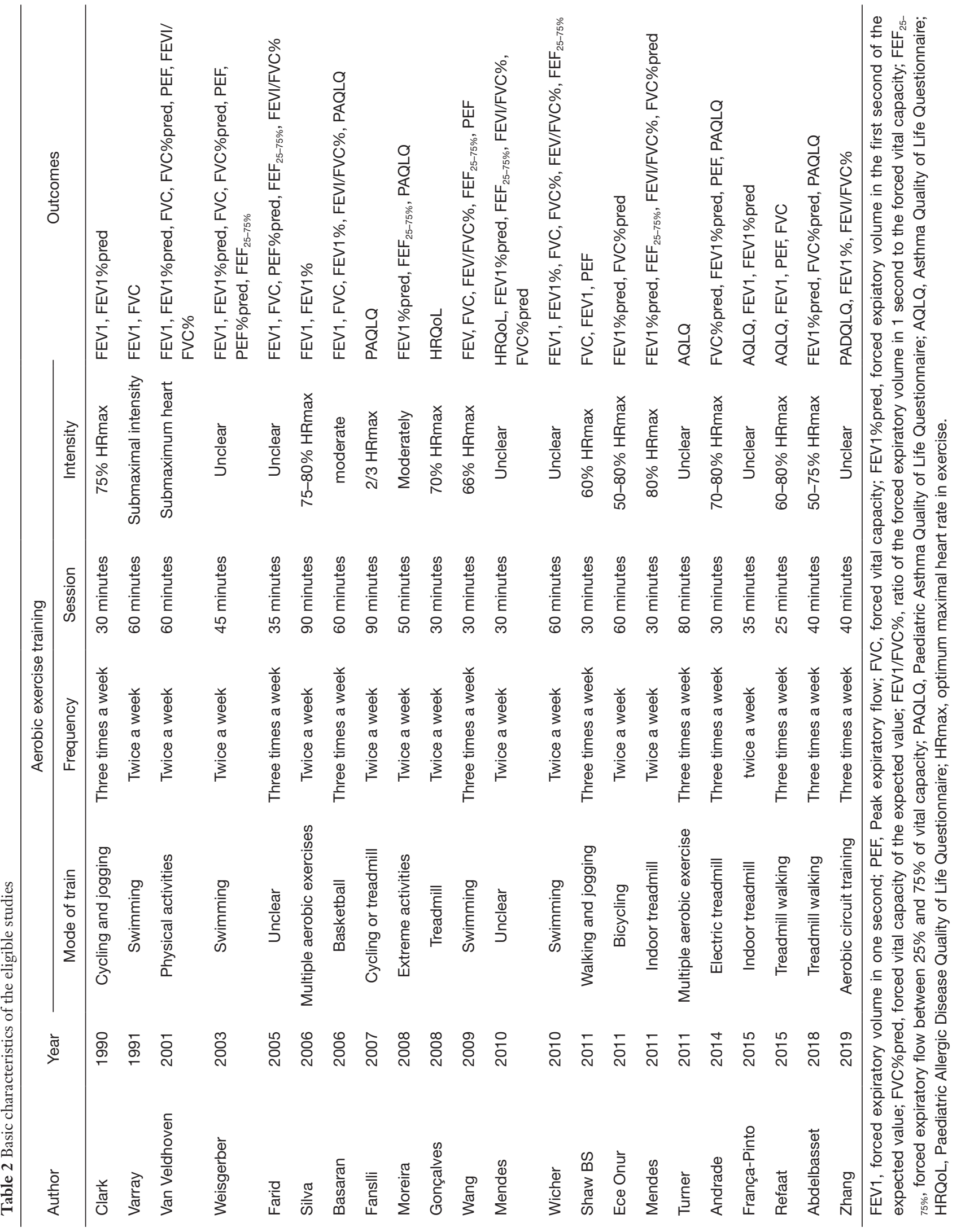




\section{FEV1}

Twelve studies (24-27,29,32,36,37,41-43) with 455 patients reporting forced expiratory volume in one second at the endpoint of exercise were meta-analyzed. No heterogeneity existed among trials $\left(\mathrm{I}^{2}=10.2 \%, \mathrm{P}=0.345\right)$, and a fixed-effects model of the pooled effect showed adequate efficiency (WMD: 0.12, 95\% CI: 0.05-0.20, P=0.011) (Figure 3) in adults and children trained with aerobic exercise. The forest plot diagrammed in Figure 3 and Egger's test demonstrated

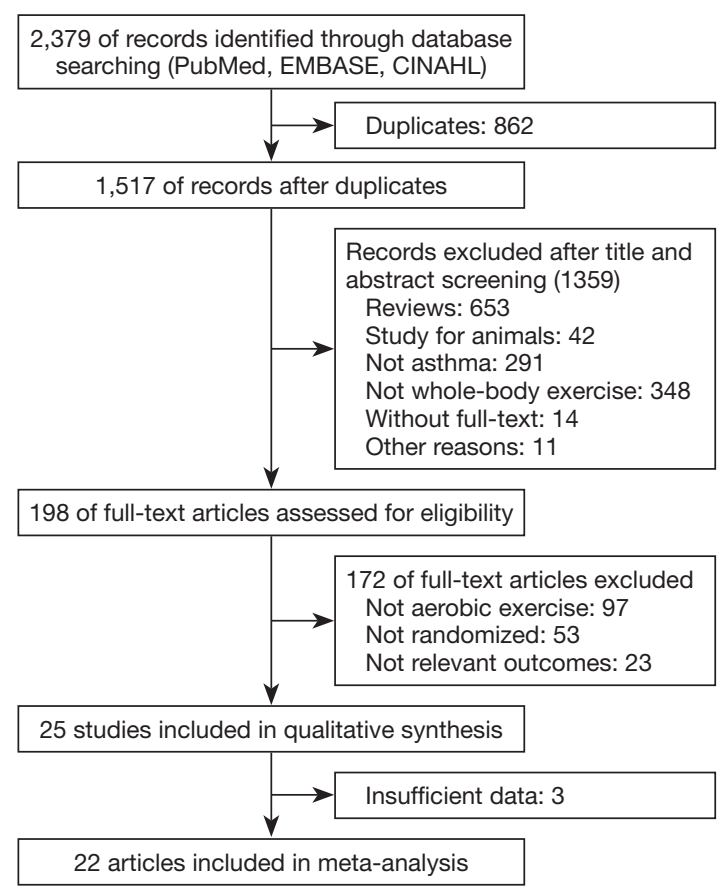

Figure 1 Diagram illustrating the study retrieval and selection. no evidence of publication bias $(\mathrm{P}=0.663)$.

\section{FEV1\%pred}

We assessed the pooled fixed-effect model of 11 studies $(24,26,27,29,30,32,33,38,42,44,45)$ with 439 participants. There was no difference between two groups after aerobic training $\left(\mathrm{I}^{2}=36.0 \%\right.$, WMD: $0.68,95 \% \mathrm{CI}:-0.64$ to 2.01 , $\mathrm{P}=0.312)$ whether in adults $(\mathrm{P}=0.808)$ or children $(\mathrm{P}=0.325)$ as participants. Egger's test displayed no publication bias $(\mathrm{P}=0.413)$ from the forest plot (Figure 3). We conducted a subgroup analysis with different modes of training. Swimming $(\mathrm{P}=0.015)$ and indoor treadmill $(\mathrm{P}=0.006)$ improved significantly (Table 3).

\section{FVC}

Ten trials (25-27,32,34,36,37,41-43) involving 373 subjects provided data on the forced vital capacity index that could be pooled with a fixed model $\left(\mathrm{I}^{2}=0.0 \%, \mathrm{P}=0.817\right)$. The meta-analysis demonstrated a significant difference in favor of aerobic exercise compared with the controls (WMD: 0.18, 95\% CI: 0.09-0.27, $\mathrm{P}=0.0001)$ in swimming ( $\mathrm{P}=0.003)$ and indoor treadmill $(\mathrm{P}=0.005)$ exercise programs (Table 3) and no publication bias using Egger's test $(\mathrm{P}=0.546)$ (Figure 3).

\section{PEF}

In six studies $(26,27,34,37,41,43)$ with 113 patients in exercise groups and 111 in control groups focused on peak expiratory flow levels of the subjects during follow up. A random-effects model $\left(\mathrm{I}^{2}=87.30 \%, \mathrm{P}=0.001\right)$ indicated that aerobic exercise improved predominantly more than the control groups (WMD: 0.66, 95\% CI: 0.24-1.09, $\mathrm{P}=0.002$ )

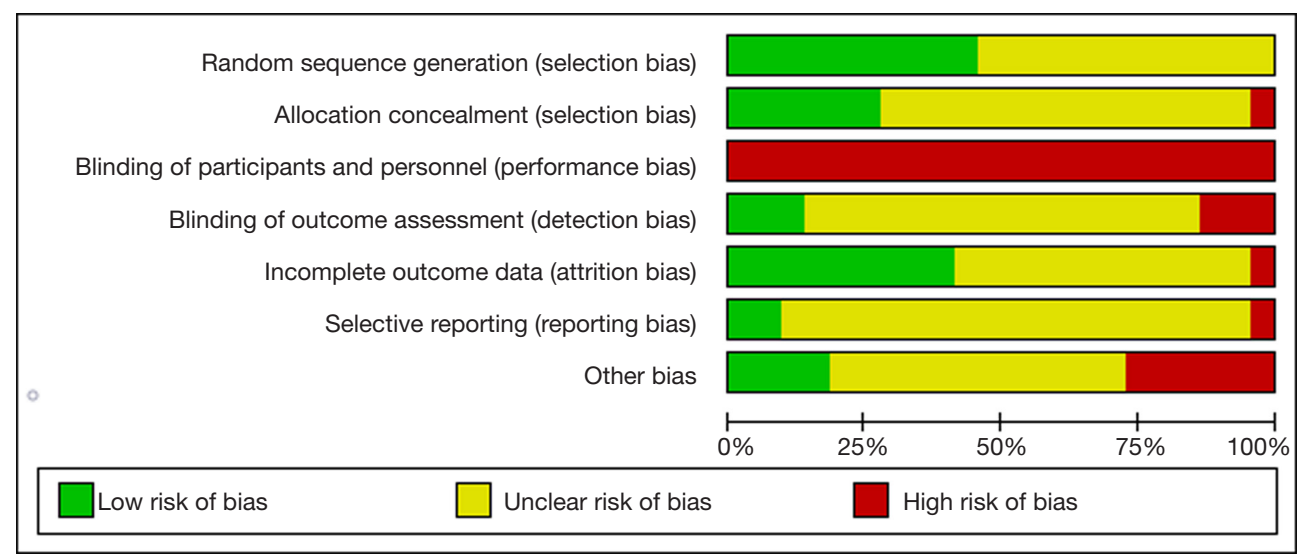

Figure 2 Risk of bias graph reviewing the authors' judgments regarding each methodological quality item presented as percentages across all of the included studies. 

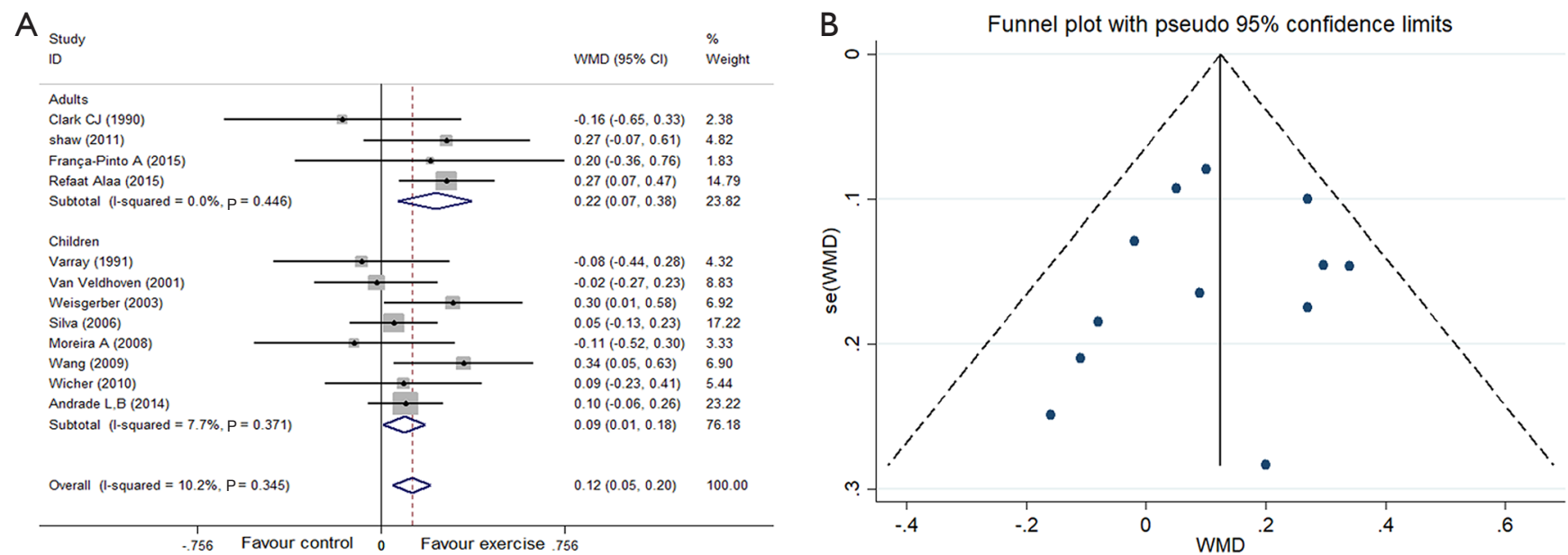

C

D

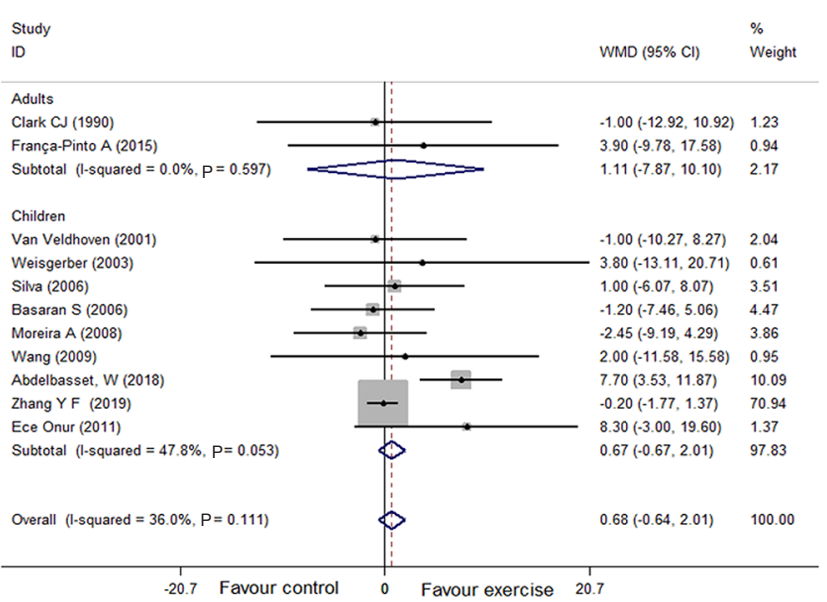

Funnel plot with pseudo $95 \%$ confidence limits

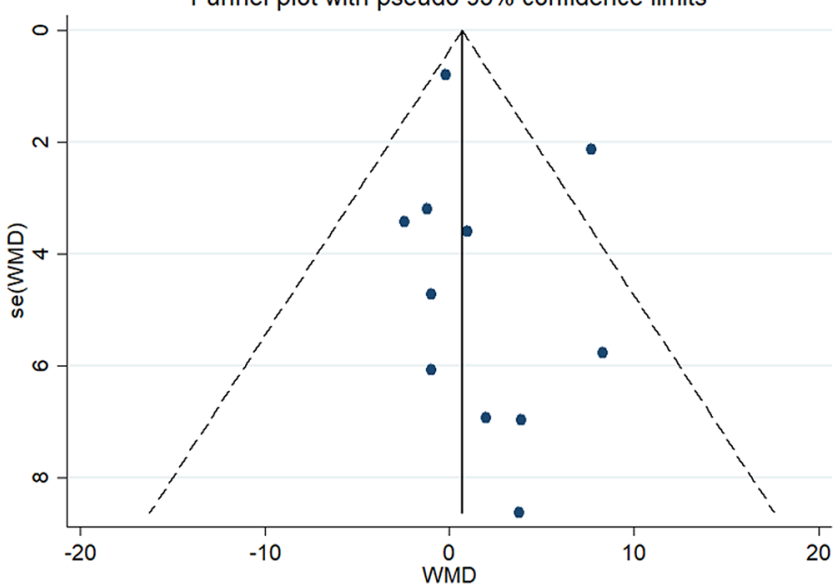

E

F
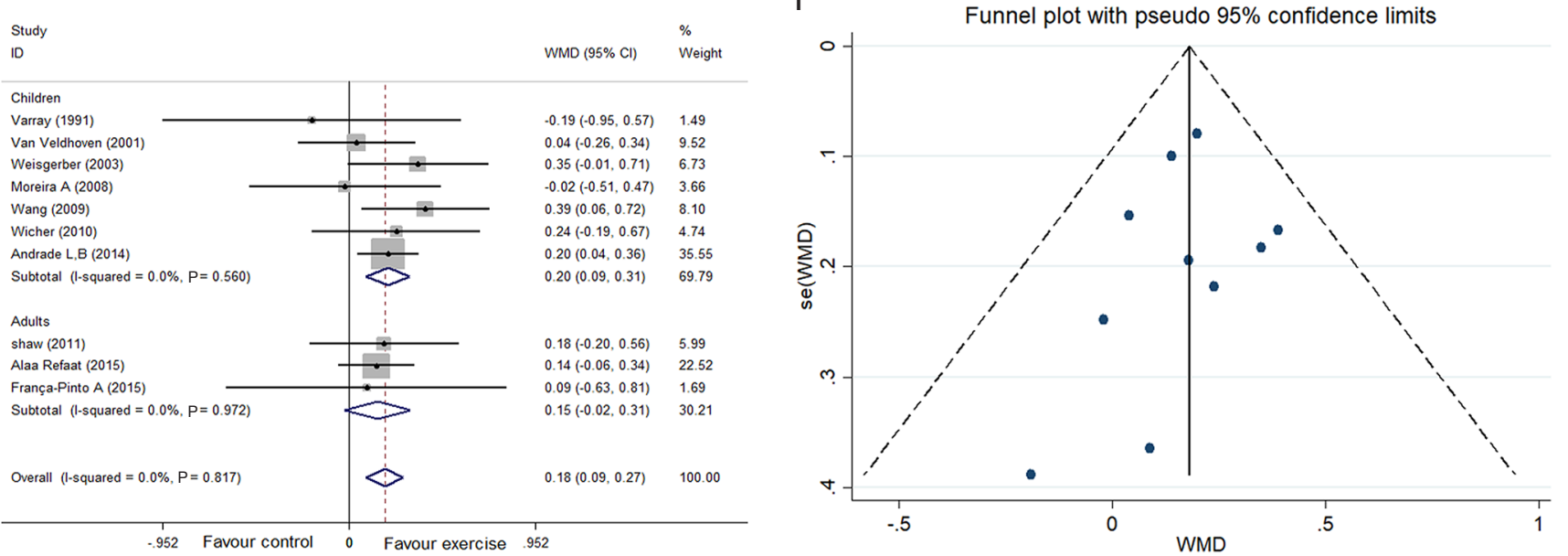

Figure 3 Meta-analysis of lung function parameters. (A) Effect of aerobic exercise on FEV1. (B) Funnel plot of FEV1 of the studies included in the meta-analysis. (C) Effect of aerobic exercise on FEV1\% pred. (D) Funnel plot of FEV1\% pred of the studies included in meta-analysis. (E) Effect of aerobic exercise on FVC. (F) Funnel plot of FVC of the studies included in the meta-analysis. 
Table 3 Subgroup analyses of the effect of aerobic exercise on pulmonary function in different training modes

\begin{tabular}{lcccc}
\hline Parameters & Mode of exercise & Number of studies & P value & Chi-squared $\left(I^{2}\right)$ \\
\hline FEV1 & Swimming & 4 & $0.015^{*}$ & $26.50 \%$ \\
& Indoor treadmill & 3 & $0.006^{*}$ & $0.00 \%$ \\
PEF & Swimming & 2 & $0.001^{*}$ & $52.20 \%$ \\
& Indoor treadmill & 2 & $0.001^{*}$ & $91.90 \%$ \\
FVC & Swimming & 4 & $0.003^{*}$ & $0.00 \%$ \\
& Indoor treadmill & 3 & $0.005^{*}$ & $0.00 \%$ \\
\hline
\end{tabular}

*, $P$ value $<0.05$ is statistically significant. Chi-squared $\left(I^{2}\right): I^{2}>50 \%$ indicates heterogeneity. FEV1, forced expiratory volume in one second; PEF, peak expiratory flow; FVC, forced vital capacity.

(Figure 4), and a subgroup analysis proved the same advantage in swimming $(\mathrm{P}=0.001)$ and indoor treadmill $(\mathrm{P}=0.001)$ groups $($ Table 3$)$.

\section{FVC\%pred}

We used a fixed-effects model for the pooled effect of FVC as a percentage of the predicted value in 6 studies $(27,31,34,28,42,44)$ including 207 participators. Aerobic exercise increased $\mathrm{FVC} \%$ pred compared with control groups $\left(\mathrm{I}^{2}=3.9 \%\right.$, WMD: 4.30, 95\% CI: 0.88-7.72, $\left.\mathrm{P}=0.014\right)$ (Figure 4).

\section{FEV1/FVC\%}

FEV1/FVC\% was included in 7 articles $(26,30,34,36,37,42,45)$ at the end of training programs, and a fixed-effects model revealed no effectiveness of aerobic exercise ( $\mathrm{I}^{2}=0.0 \%$, WMD: $0.27,95 \% \mathrm{CI}:-0.43$ to 0.98 , $\mathrm{P}=0.443)$ (Figure 4).

$\mathbf{F E F}_{25-75 \%}$

Five studies $(27,32,34,36,42)$ referred to forced expiratory flow between $25 \%$ and $75 \%$ of vital capacity at the end of exercise. A pooled fixed-effects model demonstrated a significant improvement in aerobic exercise groups $\left(\mathrm{I}^{2}=0.0 \%\right.$, WMD: 9.65, 95\% CI: 2.84-16.46, $\mathrm{P}=0.005$ ) (Figure 4).

\section{QoL}

Four of seven studies incorporated the Pediatric Asthma Quality of Life Questionnaire (PAQLQ) $(30-32,41,44)$ with children and the others reported the Asthma Quality of Life Questionnaire (AQLQ) $(42,43)$ with adults. They demonstrated that aerobic exercise groups had significantly improved quality of life among children $\left(\mathrm{I}^{2}=72.1 \%\right.$, WMD: $0.81,95 \%$ CI: $0.32-1.30, \mathrm{P}<0.001)$ and adults $\left(\mathrm{I}^{2}=0.0 \%\right.$,
WMD: 0.20, 95\% CI: 0.07-0.32, $\mathrm{P}=0.002$ ) (Figure 5).

\section{Discussion}

This meta-analysis confirmed the effectiveness of aerobic exercise training for ameliorating partial spirometry parameters (PEF, FEV1, FVC, $\mathrm{FVC} \%$ pred, and $\mathrm{FEF}_{25-75 \%}$ ) and quality of life associated with asthma. Asthmatic patients should participate in mild to moderate continuous aerobic exercise programs.

The BTS Guideline on Pulmonary Rehabilitation in Adults (48) proposed that those with chronic respiratory disease should be referred to pulmonary rehabilitation, and the routine referral of patients with asthma to pulmonary rehabilitation is not recommended based on inadequate clinical evidence. Asthmatics can be anxious about exerciseinduced bronchoconstriction (EIB) (49-52), which is why some prefer a sedentary lifestyle and avoid physical activity to deter asthmatic exacerbation $(53,54)$. Nevertheless, the increasing amount of published research proved that asthmatic patients could benefit from regular exercise training (18); the same effectiveness emerged in patients with exercise-induced asthma (55-57).

However, viewpoints concerning which exercise programs are the most beneficial did not achieve a consensus. Regarding the training modality, aerobic training is exercise that can be performed for at least 20 minutes with mild or moderate fatigue $(58,59)$. Most clinical trials designed to research chronic respiratory disease with exercise usually focus on regular aerobic training programs rather than high-intensity anaerobic exercise that can trigger exercise-induced asthma (EIA) $(51,60)$. A review by Crosbie et al. (57) reported that training intensity was the most prominent factor for increasing aerobic capacity. 


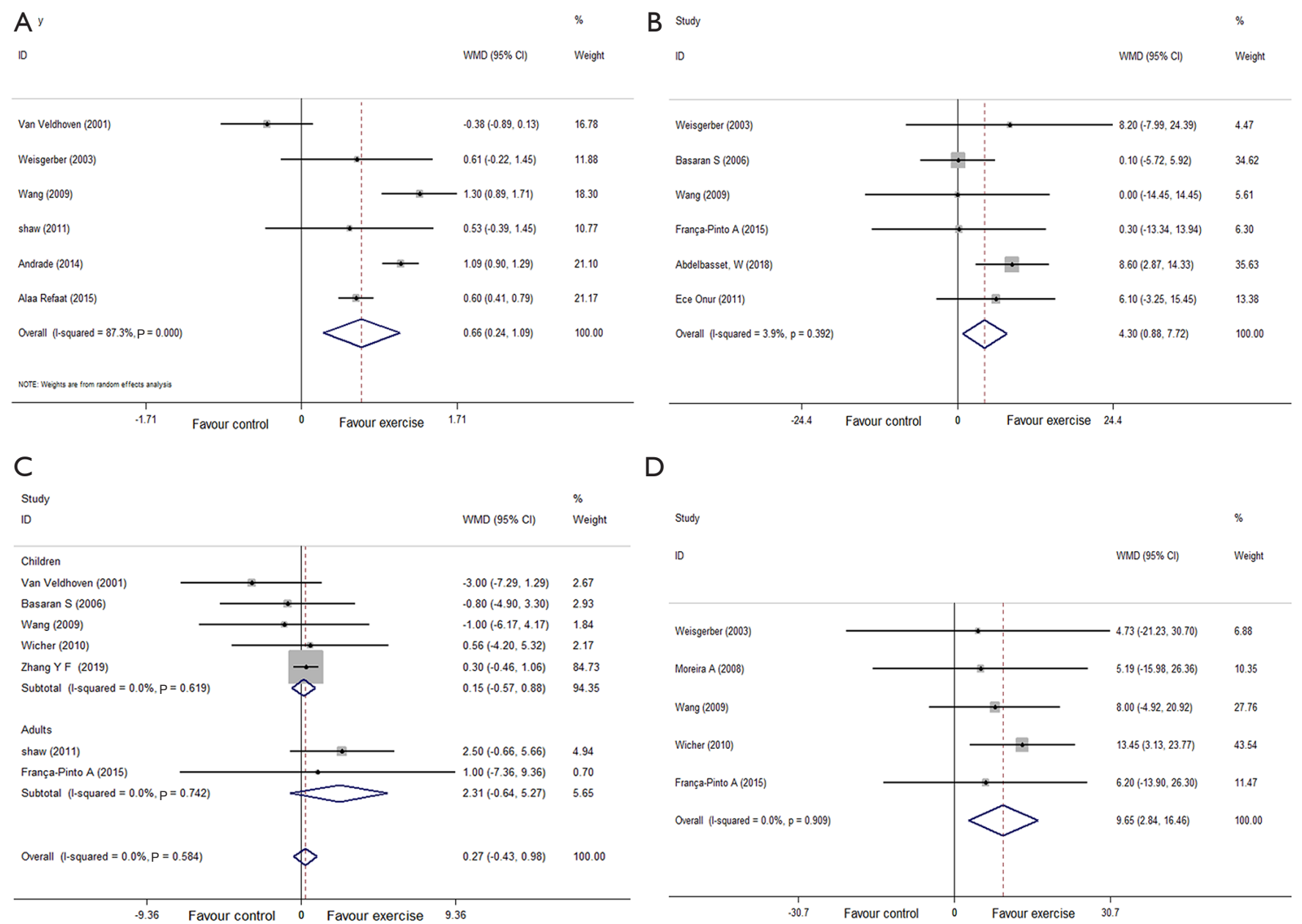

Figure 4 Meta-analysis of lung function parameters. (A) Effect of aerobic exercise on PEF. (B) Effect of aerobic exercise on FVC\% pred. (C) Effect of aerobic exercise on the ratio of the FEV1/FVC\%. (D) Effect of aerobic exercise on forced expiratory flow between $25 \%$ and $75 \%$ of vital capacity $\left(\mathrm{FEF}_{25-75 \%}\right)$.

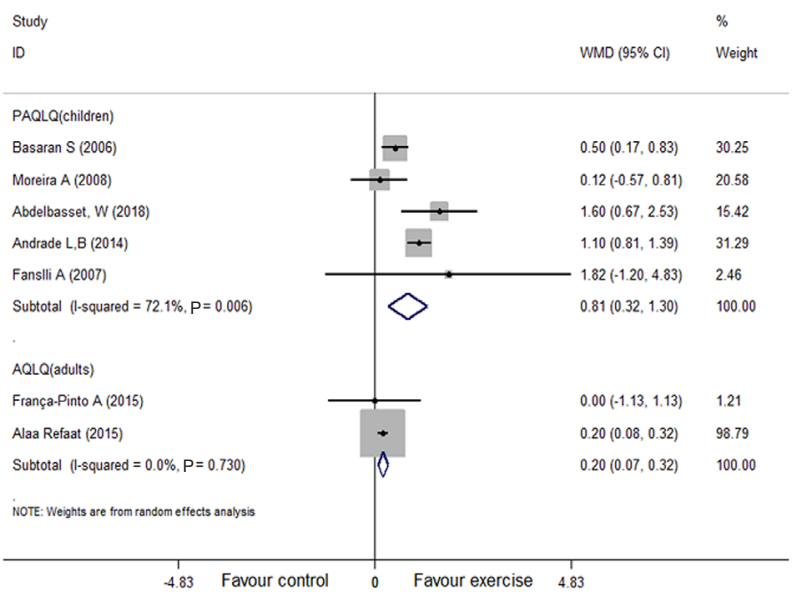

Figure 5 Effects of aerobic exercise on the PAQLQ and AQLQ.
A third session of prescribed exercise for 30 minutes each time was recommended by the American Thoracic Society/ European Respiratory Society Official Policy (61). Hence, asthmatics should participate in appropriate whole-body aerobic exercise with a moderate intensity to provide evidence-based support for clinical practice.

Spirometry parameters play an essential role in the diagnosis, severity, and prognosis of asthma and are relevant to cardiorespiratory fitness $(62,63)$. Previous studies of exercise training rarely considered lung function as the main outcome indicator and thus were insufficient to assess the effectiveness of interventions for chronic respiratory diseases (such as asthma and COPD). Accordingly, our research concentrated on lung function. In contrast to the 
Cochrane meta-analysis of Carson et al. (18), we included five additional recent studies from our search strategy and eliminated the literature with overlapping trials, unclear outcome indicators, and interventions of high-intensity volume or frequency, resulting in differences in literature inclusion. In addition, Carson et al. analyzed limited indicators of lung function (FEVI, FVC), on the basis of which we added other variables and obtained valuable results.

Forced expiratory volume in one second (FEV1) and peak expiratory flow (PEF) are the two most common indicators of the objective evaluation of asthma. The Global Initiative for Asthma (GINA) guidelines recommend spirometry to manage exacerbations of asthma that require emergency treatment or hospitalization, including specific FEV1 and PEF values as indications for admission and response to treatment $(64,65)$. Both parameters reflect airway patency and are used to measure airway function and respiratory muscle strength to indicate the degrees of airway obstructions and lesions $(63,66)$. Our meta-analysis showed noteworthy improvements in FEV1 and PEF in contrast with a review by Philipp et al. (67) that reported amelioration of FEV1 rather than PEF. This discrepancy may be due to the cooptation of newly published reports $(41,43)$ and normative difference with intervention. However, there were unexplained sources of heterogeneity with PEF, even if age, exercise patterns, follow-up time, and asthma severity were taken into account, which may be related to the time variability of the PEF measurement $(66,68)$.

Our meta-analysis observed amelioration of FVC, $\mathrm{FVC} \%$ pred, and $\mathrm{FEF}_{25-75 \%}$ after aerobic training programs, and no significant heterogeneity or selective was reported.

Both FVC and FVC\% pred are indicators of force dependence and are considerably affected by respiratory muscle function, lung compliance airway resistance, and the patient's overall health. These conditions significantly improve after using bronchodilators $(63,65,66)$. Improved in $\mathrm{FVC}, \mathrm{FVC} \%$ pred and FEV1, no significantly change was observed in $\mathrm{FEV} 1 / \mathrm{FVC} \%$ and $\mathrm{FEV}_{1} \%$ pred, which are mainly affected by airway resistance. This confirms that the $\mathrm{FEV}_{1} / \mathrm{FVC}$ ratio is not a reliable index of reversibility as FVC can increase more than FEV1, causing FEV1/ FVC to decrease in the presence of a useful degree of bronchodilation (65). $\mathrm{FEF}_{25-75 \%}$, a non-force dependent part of FVC that's flow value is mainly affected by a small airway diameter with less variability, may be useful for pediatric patients as it has greater elasticity and empties more rapidly $(69,70)$. Of the five studies included in the meta- analysis, four involved patients with children, and credible improvement was demonstrated by the pooled effect.

For further insight into the involvement of aerobic exercise in the qualified articles, age and mode of exercise were considered. There was credible improvement in FEV1, PEF, and FVC in swimming or indoor treadmill training groups. Moreover, most eligible patients had mild to moderate asthma, so regular sustained aerobic exercise for both adults and children with mild to moderate asthma is recommended, and swimming or treadmill training is a suitable choice.

The current mechanisms pertaining to improving lung function of asthmatic patients participating in aerobic exercise remain unclear. One pathophysiological study verified an increase in residual air flow and a decrease in reinforced bronchial expansion ventilation in asthmatic patients during physical exercise (71). Bronchial hyperresponsiveness (BHR) is a basic characteristic of asthma. Asthmatic animal models have systematically demonstrated that aerobic exercise reduced BHR $(72,73)$. Three studies in our meta-analysis compared BHR with the control group post-intervention and shown a trend for lower, respectively. Moreover, a literatures review of Eichelberger et al. (67). reported the same argument. Additional research observed that regular moderate aerobic training prior to allergic asthma reduced airway inflammation and remodeling (74), similar to Qin et al., who reported that low-intensity aerobic exercise training attenuated airway hyperresponsiveness, inflammation, and remodeling in a rat model of steroid-resistant asthma (75). Recent research confirmed the various molecular biological mechanisms of this effect (76). A randomized controlled trial demonstrated that supervised aerobic physical exercise for 8 weeks ( 2 times per week) could reduce asthma's pulmonary inflammation (77). According to those mechanism studies, aerobic exercise ameliorates airway inflammation, airflow obstruction, airway hyperresponsiveness, and remodeling in asthma. However, whether these effects improve lung function has not yet been determined considering that not all parameters of airway obstruction improved from our meta-analysis. Welsh et al. reported that physical activity increased expiratory reserve capacity (78). Shaw et al. (37) observed a reduction in airway obstruction and an increase in inspiratory force after aerobic training in asthmatics. Alberta et al. reported that aerobic exercise training alone increased abdominal muscular endurance (79).

The inconsistent conclusions of pulmonary function parameters may not only be related to the duration 
of aerobic training and airway variability, but also to amelioration of general health conditions, respiratory motivation, and lung compliance caused by continuous aerobic training.

Ten studies in the literature assessed quality of life associated with asthma. One (40) reported no overall scores, and another (33) presented median and quartile intervals that could not be pooled together. Routine activity, asthma symptoms, emotion, and the total quality of life score improved overall in eight trials $(30,31,33,35,39,41,43,44)$. Because different types of questionnaires were utilized, we conducted a subgroup analysis according to the PAQLQ (children) and AQLQ (adults), and higher scores indicated better quality of life. Conversely, one study that evaluated quality of life (QoL) (45) using PADQLQ scores found that higher scores indicated worse quality of life. Our metaanalysis indicated that aerobic training improved asthmarelated quality of life in both adults and children. The same conclusions were summarized in three studies $(33,35,39)$ that could not be meta-analyzed, which is consistent with other research $(67,80)$. Basaran et al. (30) indicated that changes in symptom scores significantly correlated with changes in total QoL scores, which was also reported by França-Pintoet al. (42). Zhang et al. (45) observed that asthmatics' wheezing, coughing, and sleep improved significantly in an exercise group. These reports found that regular aerobic exercise promotes the overall quality of life of asthmatic patients as demonstrated by physical fitness, asthma symptoms, and psychosocial factors $(18,19)$. This advantageous effect may also ameliorate airway hyperreactivity and pulmonary function (67).

Aerobic exercise benefits many factors related to asthma. A recent longitudinal and multi-country study reported that the advantages of physical activity may differ according to body mass index (BMI) (81). A prospective trial by Torii et al. compared morning, afternoon, and evening exercise times over a 4-week period suggested that aerobic training was most effective in the afternoon (82). van Veldhoven et al. (26) conducted a multivariate analysis of variance (MANOVA) on sex factors and confirmed that boys in an experimental group benefited more from aerobic exercise than girls. Our meta-analysis found that some parameters improved more notably in children with asthma. Relatively few studies reported the effects of aerobic exercise on adult asthma. Different responses to aerobic exercise between adults and children must be further confirmed.

None of the qualified research articles reported adverse events during aerobic exercise training except two trials.
Mendes et al. (35) observed that five patients (control group: 4; training group: 1) visited the emergency department, and eight (control group: 7; training group: 1) had asthma exacerbations. Turner et al. found that four patients (control group: 2 ; training group: 2) had asthma exacerbation during exercise (40). These studies also reported that severe asthma was associated with a higher risk of acute attacks (83). However, there was no increased risk of acute episodes due to exercise training, and aerobic exercise was well tolerated, as reported by Russell et al. (81), who found no association between physical activity and asthma incidents over 10 years, and lighter physical activity reduced asthma in middle-aged adults over time. Medication may be an important protective mechanism; the usage of prophylactic bronchodilators before each training session was mentioned in many of the eligible studies.

There are limitations to this study that merit mention. First, some relevant trials were excluded due to lack of outcomes of lung function and quality of life, or insufficient data were analyzed that could have potentially been a source of risk of bias. Second, most of the included articles had a small number of participants and evaluated only the shortterm benefits of physical training, and some studies were low quality. Finally, there was indecipherable heterogeneity among some studies although the random-effects model was used.

\section{Conclusions}

Overall, our research demonstrated that regular continuous moderate intensity aerobic exercise at least 20 minutes two or three times per week over at least four weeks improved lung function and quality of life and would be a nonpharmacological benefit for asthmatic patients. Regarding the mode of exercise, swimming or treadmill training are appropriate options.

\section{Acknowledgments}

Funding: None.

\section{Footnote}

Reporting Checklist: The authors have completed the PRISMA Checklist reporting checklist. Available at http:// dx.doi.org/10.21037/jtd-19-2813

Conflicts of Interest: All authors have completed the ICMJE 
uniform disclosure form (available at http://dx.doi. org/10.21037/jtd-19-2813). The authors have no conflicts of interest to declare.

Ethical Statement: The authors are accountable for all aspects of the work in ensuring that questions related to the accuracy or integrity of any part of the work are appropriately investigated and resolved. The study was conducted in accordance with the Declaration of Helsinki (as revised in 2013). The ethical committee approval was not required at our institution because our research is a systematic review and meta-analysis, and all analyses were based on previous published studies.

Open Access Statement: This is an Open Access article distributed in accordance with the Creative Commons Attribution-NonCommercial-NoDerivs 4.0 International License (CC BY-NC-ND 4.0), which permits the noncommercial replication and distribution of the article with the strict proviso that no changes or edits are made and the original work is properly cited (including links to both the formal publication through the relevant DOI and the license). See: https://creativecommons.org/licenses/by-nc-nd/4.0/.

\section{References}

1. The global strategy for asthma management and prevention, Global Initiative for Asthma GINA2017. Available online: http://www.ginasthma.org/

2. Zazzali JL, Broder MS, Omachi TA, et al. Risk of corticosteroid-related adverse events in asthma patients with high oral corticosteroid use. Allergy Asthma Proc 2015;36:268-74.

3. Pinto CR, Lemos AC, de Alcantara AT, et al. Systemic adverse events from inhaled corticosteroids self-reported by asthma patients: a 'real-life' cross sectional study. Rev Port Pneumol 2016;22:243-45.

4. Dai L, Huang $\mathrm{Y}$, Wang $\mathrm{Y}$, et al. Serious systemic adverse events associated with allergen-specific immunotherapy in children with asthma. Chinese Journal of Contemporary Pediatrics 2014;16:58-61.

5. Spruit MA. Pulmonary rehabilitation. Eur Respir Rev 2014;23:55-63.

6. Bhatt SP. It's Time to Rehabilitate Pulmonary Rehabilitation. Ann Am Thorac Soc2019;16:55-7.

7. Cooper CB. Exercise in chronic pulmonary disease: limitations and rehabilitation. Med Sci Sports Exerc 2001;33:S643-6.
8. Ahmed HM, Blaha MJ, Nasir K, et al. Effects of physical activity on cardiovascular disease. Am J Cardiol 2012;109:288-95.

9. Spruit MA, Singh SJ, Garvey C, et al. ATS/ERS Task Force on Pulmonary Rehabilitation. An official American Thoracic Society/European Respiratory Society statement: key concepts and advances in pulmonary rehabilitation. Am J Respir Crit Care Med 2013;188:e13-64.

10. Erikssen G, Liestol K, Bjornholt J, et al. Changes in physical fitness and changes in mortality. Lancet 1998;352:759-62.

11. Haskell WL, Lee IM, Pate RR, et al. Physical activity and public health: updated recommendation for adults from the American College of Sports Medicine and the American Heart Association. Med Sci Sports Exerc 2007;39:1423-34.

12. Westerterp KR. Pattern and intensity of physical activity. Nature 2001;410:539.

13. Karjalainen EM, Laitinen A, Sue-Chu M, et al. Evidence of airway inflammation and remodeling in ski athletes with and without bronchial hyperresponsiveness to methacholine. Am J Respir Crit Care Med 2000;161:2086-91.

14. Pastva A, Estell K, Schoeb TR, et al. Aerobic exercise attenuates airway inflammatory responses in a mouse model of atopic asthma. J Immunol 2004;172:4520-6.

15. Neder JA, Nery LE, Silva AC, et al. Short-term effects of aerobic training in the clinical management of moderate to severe asthma in children. Thorax 1999;54:202-6.

16. Ram FS, Robinson SM, Black PN. Physical training for asthma. Cochrane Database Syst Rev 2005;4:CD001116.

17. Pacheco DRR, Silva MJB, Alexandrino AMS, et al. Exercise-Related Quality of Life in Subjects with Asthma: A Systematic Review. J Asthma 2012;49:487-95.

18. Carson KV, Chandratilleke MG. Physical training for asthma. Cochrane Database Syst Rev 2013;30:CD001116.

19. Francisco CO, Bhatawadekar SA. Effects of physical exercise training on nocturnal symptoms in asthma: Systematic review. PLoS One 2018;13:e204953.

20. Avallone KM, McLeish AC. Asthma and aerobic exercise: A review of the empirical literature. J Asthma 2013;50:109-16.

21. Latorre-Román PÁ, Navarro-Martínez AV, García-Pinillos F. The effectiveness of an indoor intermittent training program for improving lung function, physical capacity, body composition and quality of life in children with asthma. J Asthma 2014;51:544-51.

22. Olivo SA, Macedo LG, Gadotti IC, et al. Scales to assess the quality of randomized controlled trials: a systematic 
review. Phys Ther 2008;88:156-75.

23. Higgins JPT, Green S. Cochrane handbook for systematic reviews of interventions version 5.1.0 updated March 2011: The Cochrane Collaboration, 2011. Available online: http://www.cochrane-handbook.org

24. Cochrane LM, Clark CJ. Benefits and problems of a physical training programme for asthmatic patients. Thorax 1990;45:345-51.

25. Varray AL, Mercier JG, Terral CM, et al. Individualised aerobic and high intensity training for asthmatic children in an exercise readaptation program-Is training always helpful for better adaptation to exercise? Chest 1991;99:579-86.

26. van Veldhoven NH, Vermeer A, Bogaard JM, et al. Children with asthma and physical exercise: effects of an exercise programme. Clin Rehabil 2001;15:360-70.

27. Weisgerber MC, Guill M, Weisgerber JM, et al. Benefits of swimming in asthma: effect of a session of swimming lessons on symptoms and PFTs with review of the literature. J Asthma 2003;40:453-64.

28. Farid R, Azad FJ, Atri AE, Rahimi MB, et al. Effect of aerobic exercise training on pulmonary function and tolerance of activity in asthmatic patients. Iran J Allergy Asthma Immunol 2005;4:133-8.

29. Silva CS, Torres LAGMM, Rahal A, et al. Comparison of morning and afternoon exercise training for asthmatic children. Braz J Med Biol Res 2006;39:71-8.

30. Basaran S, Guler-Uysal F, Ergen N, et al. Effects of physical exercise on quality of life, exercise capacity and pulmonary function in children with asthma. J Rehabil Med 2006;38:130-5.

31. Fanelli A, Cabral ALB, Neder JA, et al. Exercise training on disease control and quality of life in Asthmatic children. Med Sci Sports Exerc 2007;39:1474-80.

32. Moreira A, Delgado L, Haahtela T, et al. Physical training does not increase allergic inflammation in asthmatic children. Eur Respir J 2008;32:1570-5.

33. Gonçalves RC, Nunes MPT, Cukier A, et al. Effects of an aerobic physical training program on psychosocial characteristics, quality of life, symptoms and exhaled nitric oxide in individuals with moderate or severe persistent asthma. Revista Brasileira de Fisioterapia 2008;12:127-135.

34. Wang JS, Hung WP. The effects of a swimming intervention for children with asthma. Respirology 2009; 14:838-42.

35. Mendes FA, Gon'alves RC, Nunes MP, et al. Effects of aerobic training on psychosocial morbidity and symptoms in patients with asthma: a randomized clinical trial. Chest
2010;138:331-7.

36. Wicher IB, Ribeiro MA, Marmo DB, et al. Effects of swimming on spirometric parameters and bronchial hyperresponsiveness in children and adolescents with moderate persistent atopic asthma. J Pediatr (Rio J) 2010;86:384-90.

37. Shaw BS, Shaw I. Pulmonary function and abdominal and thoracic kinematic changes following aerobic and inspiratory resistive diaphragmatic breathing training in asthmatics. Lung 2011;189:131-9.

38. Onur E, Kabaroğlu C, Günay O, et al. The beneficial effects of physical exercise on antioxidant status in asthmatic children. Allergol Immunopathol (Madr) 2011;39:90-95.

39. Mendes FAR, Almeida FM, Cukier A, et al. Effects of Aerobic Training on Airway Inflammation in Asthmatic Patients. Med Sci Sports Exerc 2011;43:197-203.

40. Turner S, Eastwood P, Cook A, et al. Improvements in Symptoms and Quality of Life following Exercise Training in Older Adults with Moderate/Severe Persistent Asthma. Respiration 2011;81:302-10.

41. Andrade LB, Britto MC, Lucena-Silva N, et al. The efficacy of aerobic training in improving the inflammatory component of asthmatic children. Randomized trial. Respir Med 2014;108:1438-45.

42. França-Pinto A, Mendes FA, de Carvalho-Pinto RM, et al. Aerobic training decreases bronchial hyperresponsiveness and systemic inflammation in patients with moderate or severe asthma: A randomized controlled trial. Thorax 2015;70:732-9.

43. Alaa R, Mohamed G. Effect of physical training on healthrelated quality of life in patients with moderate and severe asthma. Egyptian Journal of Chest Diseases and Tuberculosis 2015;647:761-6.

44. Abdelbasset WK, Alsubaie SF, Tantawy SA, et al. Evaluating pulmonary function, aerobic capacity, and pediatric quality of life following a 10-week aerobic exercise training in school-aged asthmatics: a randomized controlled trial. Patient Prefer Adherence 2018;12:1015-23.

45. Zhang YF, Yang LD. Exercise training as an adjunctive therapy to montelukast in children with mild asthma: A randomized controlled trial. Medicine 2019;98:e14046.

46. Jackson AS. Estimating maximum heart rate from age: is it a linear relationship? Med Sci Sports Exerc 2007;39:821.

47. Antonacci L, Mortimer LF, Rodrigues VM, et al. Competition, estimated, and test maximum heart rate. J Sports Med Phys Fitness 2007;47:418-21. 
48. Bolton CE, Bevan-Smith EF. British Thoracic Society guideline on pulmonary rehabilitation in adults. Thorax 2013;68:887-8.

49. Weiler JM, Anderson SD, Randolph C, et al. Pathogenesis, prevalence, diagnosis, and management of exerciseinduced bronchoconstriction: a practice parameter. Ann Allergy Asthma Immunol 2010;105:S1-47.

50. Ali Z. How to Diagnose Exercise Induced Asthma? Asian J Sports Med 2011;2:63-7.

51. Garcia-Aymerich J, Varraso R, Anto JM, et al. Prospective study of physical activity and risk of asthma exacerbations in older women. Am J Respir Crit Care Med 2009;179:999-1003.

52. Ritz T, Rosenfield D, Steptoe A. Physical activity, lung function, and shortness of breath in the daily life of individuals with asthma. Chest 2010;138:913-8.

53. Clark CJ. Asthma and exercise: A suitable case for rehabilitation? Thorax 1992;47:765-7.

54. Teramoto M, Moonie S. Physical activity participation among adult Nevadans with self-reported asthma. J Asthma 2011;48:517-22.

55. Henriksen JM, Nielsen TT, Dahl R. Effects of physical training on plasma citrate and exercise-induced asthma. Scand J Clin Lab Invest 1981;41:225-9.

56. Ram FS, Robinson RM, Black PN. Effects of physical training in asthma: a systematic review. Br J Sports Med 2000;34:162-7.

57. Crosbie A. The effect of physical training in children with asthma on pulmonary function, aerobic capacity and health-related quality of life: a systematic review of randomized control trials. Pediatr Exerc Sci 2012;24:472-89.

58. ACSM. American college of sports medicine position stand. The recommended quantity and quality of exercise for developing and maintaining cardiorespiratory and muscular fitness, and flexibility in healthy adults. Med Sci Sports Exerc 1998;30:975-91.

59. Mezzani A, Hamm LF. Aerobic exercise intensity assessment and prescription in cardiac rehabilitation: a joint position statement of the European Association for Cardiovascular Prevention and Rehabilitation, the American Association of Cardiovascular and Pulmonary Rehabilitation and the Canadian Association of Cardiac Rehabilitation. Eur J Prev Cardiol 2013;20:442-67.

60. Khajotia R. Exercise-induced asthma: Fresh insights and an overview. Malays Fam Physician 2008;3:21-4.

61. Rochester CL, Vogiatzis I. An Official American Thoracic Society/European Respiratory Society Policy Statement:
Enhancing Implementation, Use, and Delivery of Pulmonary Rehabilitation. Am J Respir Crit Care Med 2015;192:1373-86.

62. Gao Y, Han JN. Guidebooks of pulmonary function-Lung Volume Measurements China. Chin J of Tuber Respir Dis 2015;38:121-48.

63. Melén E, Guerra S. Recent advances in understanding lung function development. F1000Res 2017;6:726.

64. Global Initiative for Asthma. Pocket guide for asthma management and prevention. Available online: http:// www.ginasthma.org/guidelines-pocket-guidefor-asthmamanagement.html..

65. Ruppel GL, Enright PL. Pulmonary function testing. Respir Care 2012;57:165-75.

66. Culver BH, Graham BL, Coates AL. Recommendations for a Standardized Pulmonary Function Report. An Official American Thoracic Society Technical Statement. Am J Respir Crit Care Med 2017;196:1463-72.

67. Eichenberger PA, Diener SN, Kofmehl R, et al. Effects of exercise training on airway hyperreactivity in asthma: a systematic review and meta-analysis. Sports Med 2013;43:1157-70.

68. Liang XL, Zheng JP. Research progress of pulmonary function testing in 2017. Chin J Pract Inter Med 2018;388:681-4.

69. Ramsey CD, Celedon JC, Sredl DL, et al. Predictors of disease severity in children with asthma in Hartford, Connecticut. Pediatr Pulmonol 2005;39:268-75.

70. Keen C, Olin AC, Wennergren G, et al. Small airway function, exhaled NO and airway hyper-responsiveness in paediatric asthma. Respir Med 2011;105:1476-84.

71. William M, Katch F, Katch V. Essentials of exercise physiology. USA: Williams and Wilkins, 2000.

72. Silva RA, Vieira RP, Duarte ACS, et al. Aerobic training reverses airway inflammation and remodelling in an asthma murine model. Eur Respir J 2010;35:994-1002.

73. Olivo CR, Vieira RP, Arantes-Costa FM, et al. Effects of aerobic exercise on chronic allergic airway inflammation and remodelling in guinea pigs. Respir Physiol Neurobiol 2012;182:81-7.

74. de Araújo CC, Marques PS, Silva JD, et al. Regular and moderate aerobic training before allergic asthma induction reduces lung inflammation and remodeling. Scand J Med Sci Sports 2016;26:1360-72.

75. Qin Q, Chen X, Feng J, et al. Low-intensity aerobic exercise training attenuates airway inflammation and remodeling in a rat model of steroid-resistant asthma. Chinese Medical Journal 2014;127:3058-64. 
76. Almeida-Oliveira AR, Aquino-Junior. Effects of aerobic exercise on molecular aspects of asthma: involvement of SOCS-JAK-STAT. Exerc Immunol Rev 2019;25:50-62.

77. Gomes ELFD, Carvalho CRF, Sobral PSF, et al. Active Video Game Exercise Training Improves the Clinical Control of Asthma in Children: Randomized Controlled Trial. PLoS One 2015;10:e0135433.

78. Welsh L, Kemp JG, Roberts RG. Effects of physical conditioning on children and adolescents with asthma. Sports Med 2005;35:127-41.

79. Alberga AS, Prud'homme D. Effects of aerobic training, resistance training, or both on cardiorespiratory and musculoskeletal fitness in adolescents with obesity: the HEARTY trial. Appl Physiol Nutr Metab 2016;41:255-65.

Cite this article as: $\mathrm{Wu} \mathrm{X}, \mathrm{Gao} \mathrm{S}$, Lian Y. Effects of continuous aerobic exercise on lung function and quality of life with asthma: a systematic review and meta-analysis. J Thorac Dis 2020;12(9):4781-4795. doi: 10.21037/jtd-19-2813
80. Meyer A, Günther S, Volmer T, et al. A 12-month, moderate-intensity exercise training program improves fitness and quality of life in adults with asthma: a controlled trial. BMC Pulm Med 2015;15:56.

81. Russell MA, Janson C, Real FG, et al. Physical activity and asthma: A longitudinal and multi-country study. J Asthma 2017;54:938-45.

82. Torii J, Shinkai S, Hino S, et al. Effect of time of day on adaptive response to a 4-week aerobic exercise program. J Sports Med Phys Fitness 1992;32:348-52.

83. Zheng XY, Xu YJ, Guan WJ, et al. Regional, age and respiratory-secretion-specific prevalence of respiratory viruses associated with asthma exacerbation: a literature review. Arch Virol 2018;163:845-53. 